\title{
Bone mineral density and markers of bone turnover in young adult survivors of childhood lymphoblastic leukaemia
}

\author{
Jantine J. G. Hoorweg-Nijman*, Gabriella Kardos*, \\ Jan C. Roos†, Henrika J. van Dijk*, Coen \\ Netelenbos $\ddagger$, Corrie Popp-Snijders $\ddagger$, Christine M. \\ de Ridder* and Henriëtte A. Delemarre-van de Waal* \\ *Department of Paediatrics, †Department of Nuclear \\ Medicine and $\ddagger$ Department of Endocrinology, Research \\ Institute for Endocrinology, Reproduction and \\ Metabolism, Vrije Universiteit, Amsterdam, The \\ Netherlands.
}

(Received 20 April 1998; returned for revision 24 June 1998; finally revised 24 July 1998; accepted 10 September 1998)

\section{Summary}

OBJECTIVE In order to determine if a serious disease like childhood acute lymphoblastic leukaemia (ALL) and the treatment necessary to cure the patients has long term effects on bone mass, we assessed bone mineral density (BMD) and several parameters involved in bone formation in a group of young adult survivors of ALL.

DESIGN AND PATIENTS Fourteen male and ten female survivors, treated for ALL in childhood, were cross-sectionally studied, at a mean age of 25.1 years (range 201-34.9). All patients, except for two, had received cranial irradiation as part of their treatment (mean radiation dose 2460 cGy).

MEASUREMENTS Height and weight were measured. Bone mineral density (BMD) was assessed using dual energy X-ray absorptiometry in the lumbar spine, femoral neck, femoral trochanter and at 1/3 distal and ultradistal in the radius. Early morning serum levels of LH, FSH, oestradiol or testosterone, IGF-1 and IGF-BP3 were determined as well as several specific markers of bone turnover.

RESULTS Mean height, expressed as standard deviation score (SDS) was -1.12 , significantly reduced. $B M D$ in the lumbar spine, femoral neck and at $1 / 3$

Correspondence: Dr J. J. G. Hoorweg-Nijman, Department of Paediatrics, University Hospital Vrije Universiteit, P.O. Box 7057, 1007 MB Amsterdam, The Netherlands. Fax: +31 204440849. distal and ultradistal in the radius, was significantly lower compared to the reference population $(P<0.05)$. No correlation was found between the BMD values and the cumulative dose of administered cytotoxic drugs, the age at diagnosis of ALL or the duration of follow-up. Mean IGF-1 and IGF-BP3 SDS-scores were -1.24 and -0.78 respectively, significantly reduced. GH stimulation tests performed in a subgroup of 9 patients showed an insufficient peak GH response in at least one test in all tested patients. The values of LH, FSH oestradiol or testosterone were within the normal adult range. Serum markers of bone formation and bone resorption were in the normal range, indicating that bone turnover was normal at the time of the study.

CONCLUSIONS Bone development in patients cured of acute lymphoblastic leukaemia is disturbed, resulting in a significantly reduced bone mineral density. Impaired growth hormone activity, as a long term effect of cranial irradiation, may be one of the underlying causes as well as the illness itself and the administered cytotoxic drugs. Since a reduced bone mineral density predispose patients to osteoporosis, intervention in order to improve bone mass should be considered.

With current treatment, more than $70 \%$ of children with acute lymphoblastic leukaemia (ALL) will be cured of their disease in The Netherlands (Veerman et al., 1996). With increasing numbers of survivors the long term side effects of the disease and treatment become more important; one of the side effects may be oesteoporosis.

Under healthy conditions during childhood and adolescence, bone mineral density (BMD) gradually increases until peak bone mass is reached by young adulthood (Ott, 1990; Boot et al., 1997). Bone mass is the result of bone formation and bone resorption. During childhood and adolescence bone formation prevails, while after the age of about 40 years bone resorption predominates. Peak bone mass is indicated to be an important determinant of the development of osteoporosis later in life, decreased peak bone mass being associated with an increased risk of osteoporosis (Johnston \& Slemenda, 1993; Sabatier et al., 1996). 
Chronic diseases in childhood such as type 1 diabetes mellitus, chronic inflammatory bowel disease and asthma, may have a negative impact on bone mineralization (Wiske et al., 1982; Kirschner et al., 1978; Boot, 1997). Inappropriate bone formation may be due to a direct effect of these illnesses and to treatment modalities. Little is known about the short and long term influences of ALL on bone mineralization in children. These children have a period of serious illness and undergo a 2 to 3 year period of intensive treatment. During this period several developmental processes such as growth, pubertal maturation and bone mineralization slow down (Moëll et al., 1988; Logghe et al., 1988; Halton et al., 1996). Generally, once cured, normalization of most processes occurs, although several treatments can result in persistent organ failure e.g. pituitary deficiency after cranial irradiation and gonadal failure in males treated with alkylating drugs (Shalet, 1989; Hoorweg-Nijman et al., 1992).

The question arises whether decreased bone mineralization during a period of illness will be restored or whether this period will result in a sustained inappropriate bone mass. Therefore, BMD as well as different factors involved in bone metabolism have been investigated in a group of young adult survivors of childhood ALL.

\section{Patients and methods}

\section{Patients}

The group of former ALL patients comprised 24 young adults (14 males and 10 females) with a mean age of $25 \cdot 1$ years (range 20.1-34.9). They had been treated at the paediatric department of the University Hospital Vrije Universiteit between 1972 and 1990. The age at diagnosis and cessation of treatment, the treatment protocol, the dose and location of irradiation and the height of the parents were recorded from the patients files. The patients were treated with different treatment protocols. In general, the schedule started with an intensive induction period, followed by maintenance therapy for 2 to 3 years; it included systemic administration of corticosteroids, vincristine, methotrexate and 6-mercaptopurine in all patients. In some patients other cytotoxic drugs were added. In 21 out of the 24 patients the cumulative dose of the cytotoxic drugs $\left(\mathrm{mg} / \mathrm{m}^{2}\right)$ could be calculated. To be able to compare the different forms of corticosteroids used in the treatment protocols we recalculated the different potencies of the drugs to the potency of hydrocortisone. All patients, except two, received cranial irradiation as part of their treatment. The irradiation dose in these patients varied between 1800 and 3000 cGy (mean 2460 cGy). In one patient spinal irradiation was added (1950cGy); one received craniospinal irradiation during recurrence of the ALL ( 2520 cGy cranial and 1980 cGy spinal irradiation) and one received irradiation of the testes twice (2000 and $1800 \mathrm{cGy}$ ). This latter patient is receiving testosterone replacement because of gonadal insufficiency. Five females are using oral contraceptives and one female has a primary amenorrhoea. A positive family history of osteoporosis was present in two patients; in one, a grandmother, and in the other an aunt was known to have osteoporosis.

In a subgroup of patients additional investigation was performed to evaluate growth hormone $(\mathrm{GH})$ status by stimulation tests. These patients were selected because they had BMD-Z score values $<1$ in at least 2 of the 3 skeleton regions, i.e. lumbar spine, femur or radius $(n=8)$ or had an IGF-1 SDS value $<-2(n=1)$.

To evaluate biochemical bone markers a control group was created; this group consisted of 24 age and sex matched healthy volunteers.

Written informed consent was obtained from all patients and controls. The study protocol had been approved by the Medical Ethical Committee of the University Hospital Vrije Universiteit.

\section{Clinical assessments}

The patients were investigated in the morning. Height and weight distribution were compared with references for the Dutch population (Roede \& van Wieringen, 1985). Height was expressed as height standard deviation score (SDS). Target height (TH) was calculated by the formula (paternal height + maternal height +12$) / 2+3$ for males and (paternal height + maternal height -12$) / 2+3$ for females; TH-SDS was calculated by the formula ( $\mathrm{TH}-182,0) / 6,7$ for males and (TH - 168, 3)/6,2 for females (Roede \& van Wieringen, 1985). Weight ranges were also evaluated using body mass index (BMI) as calculated weight/height ${ }^{2}\left(\mathrm{~kg} / \mathrm{m}^{2}\right)$. Pubertal stage was assessed according to the Tanner method (Tanner, 1962).

\section{Bone mineral density (BMD)}

BMD was estimated using dual energy x-ray absorptiometry (DXA), Hologie QDR-2000. At present DXA is the method of choice to measure BMD (Mazess et al., 1990). BMD $\left(\mathrm{g} / \mathrm{cm}^{2}\right)$ of the lumbar spine L1-L4 (LS), femoral neck (FN) and femoral trochanter (FT), and at $1 / 3$ of the distal end of the ulna in the radius (1/3 radius) and ultra distal in the radius (UD) were measured. The BMD values were expressed as Z-scores, adjusted for sex and age, according to a reference database provided by the manufacturer; for the LS and femur described by Kelly (1990). The coefficient of variation for BMD measurements is $1 \%$ (Wahner \& Fogelman, 1994).

\section{Biochemical assessments}

Blood samples were taken after an overnight fast between 08.00 
and 10.00 for determination of calcium $(\mathrm{Ca})$, phosphate $(\mathrm{P})$, alkaline phosphatase (ALP), luteinizing hormone (LH), follicle stimulating hormone (FSH), oestradiol (E2) or testosterone (T), insulin-like growth factor (IGF-1), insulin-like growth factor binding protein 3 (IGF-BP3), procollagen type $1 \mathrm{C}$-terminal propeptide (PICP), cross linked telopeptide of type 1 collagen (ICTP), osteocalcin (osteoc) and bone alkaline phosphatase (BALP). A first morning voiding urine sample was collected to determine calcium/creatinine $(\mathrm{Ca} /$ creat) ratio. $\mathrm{LH}, \mathrm{FSH}$ and $\mathrm{E} 2$ values were not determined in the females using oral contraceptives $(n=5)$. In the other females $(n=5)$ these values were measured in the follicular phase of the menstrual cycle.

Two GH stimulation tests were performed in a subgroup of 9 patients. The maximum peak GH response was determined during an insulin tolerance test (blood glucose nadir $<2.0 \mathrm{mmol} / \mathrm{l}$ ) and, on a separate occasion, after $100 \mu \mathrm{g}$ GH-releasing hormone (GHRH-test).

The serum Ca, P, ALP as well as Ca and creatinine in urine were measured with routine laboratory methods LH and FSH were determined by immunoradiometric assays (Luminescence, Amerlite Amersham, UK), E2 and T by radioimmunoassays (Sorin Biomedica, Saluggia, Italy and DPC, Los Angeles, USA, respectively), IGF-1 by immunoradiometric assay after acidethanol extraction of binding proteins (DSL, Webster, Texas), IGF-BP3 by immunoradiometric assay (DSL, Webster, Texas) and GH by immunometric assay (Sorin Biomedica, Saluggia, Italy); reference values of the hormonal parameters were validated in our laboratory. IGF-1 values decrease markedly from the age of 20 to 35 years; IGF-BP3 values decrease as well, but to a lesser extent (de Boer et al., 1994b). In addition, the values at different ages are different for males and females. The values were therefore expressed as SDS-scores, adjusted for sex and age. P1CP was measured by radioimmunoassay (Orion Diagnostica Espoo, Finland), osteocalcin by immunoradiometric assay (Biosource Diagnostics Fleuris, Belgium) and BALP by a wheat germ agglutinin precipitation assay (Bouman et al., 1996). The biochemical bone markers were compared to an age and sex matched control group.

\section{Statistical analysis}

95\% confidence intervals (CI) were calculated. CI not containing zero, were considered statistically significant. MannWhitney U tests were performed to compare characteristics of the male and female patients and to compare characteristics of the subgroup with the total group of patients. Correlation analysis was performed using Pearson correlation coefficients. Student's $t$-tests were used to compare bone marker values between patients and controls. $P$ values $<0.05$ were considered statistically significant (computer software package NCSS, version 6.0, author J. L. Hinze).

\section{Results}

The clinical characteristics of the patients are shown in Table 1. Mean height SDS of the total group of patients was $-1 \cdot 12$ (range $-3 \cdot 3$ to $+0.50 ; 95 \% \mathrm{CI}:-1.51$ to -0.72 ). Mean target height SDS of the studied patients was 0.01 (range -1.94 to $1.24 ; 95 \%$ CI: -0.37 to $+0 \cdot 40$ ). Height in the patients was significantly reduced compared to the normal Dutch population and to the target height. Mean height in the men was, compared to the normal Dutch population, reduced by $8.4 \mathrm{~cm}(173.6 \mathrm{vs}$. $182.0 \mathrm{~cm})$, in women by $5.8 \mathrm{~cm}(162.5 \mathrm{vs} 168.3 \mathrm{~cm})$. Weight related to age was in the normal range. Mean BMI, in men and women respectively, 23.7 and $26.1 \mathrm{~kg} / \mathrm{m}^{2}$, were in the upper-normal range (Dutch reference range 20-26.9).

The BMD values of the different regions, expressed in Zscores, are shown in Fig. 1. In the LS, mean BMD Z-score was -1.07 (range -4.15 to $+0.47 ; 95 \% \mathrm{CI}-1.56$ to -0.57 ); in the FN this value was -1.07 (range -3.60 to $+0.98 ; 95 \% \mathrm{CI}-1.59$ to -0.55 ); in the FT -0.55 (range -2.77 to $+2.11 ; 95 \% \mathrm{CI}$ -1.11 to +0.33 ); in the $1 / 3$ radius -1.76 (range -4.86 to $+0.39 ; 95 \% \mathrm{CI}-2.28$ to -1.24$)$ and in the UD radius -1.44 (range -4.46 to $+0 \cdot 38 ; 95 \% \mathrm{CI}-2 \cdot 00$ to -0.87 ). The Z-scores for $\mathrm{LS}, \mathrm{FN}, 1 / 3$ radius and UD radius, but not for $\mathrm{FT}$, were significantly lower than in the reference population $(P<0 \cdot 05)$. Most of the measured values were below the mean of the reference population i.e. below a Z-score of 0 . Although the male patients were significantly younger at diagnosis and at

Table 1 Clinical characteristics of 14 male and 10 female patients cured of ALL, Mean (Range).

\begin{tabular}{lcc}
\hline & Male & Female \\
\hline Age at study (years) & $23 \cdot 4$ & $27 \cdot 4 \dagger$ \\
& $(20 \cdot 1-30 \cdot 2)$ & $(21 \cdot 4-34 \cdot 9)$ \\
Age at diagnosis (years) & $6 \cdot 8$ & $9 \cdot 9 \dagger$ \\
Period of follow-up (years)* & $(1 \cdot 7-14 \cdot 6)$ & $(3 \cdot 9-15 \cdot 9)$ \\
& $13 \cdot 4$ & $15 \cdot 0$ \\
Height (cm) & $(5 \cdot 3-20 \cdot 4)$ & $(6 \cdot 7-21 \cdot 7)$ \\
& $173 \cdot 6$ & $162 \cdot 5 \dagger$ \\
Height SDS & $(159 \cdot 7-180 \cdot 4)$ & $(152 \cdot 3-171 \cdot 1)$ \\
& $-1 \cdot 25$ & -0.93 \\
Weight $(\mathrm{kg})$ & $(-3 \cdot 3-+0 \cdot 1)$ & $(-2 \cdot 6-+0 \cdot 5)$ \\
& $71 \cdot 8$ & $68 \cdot 3$ \\
Body mass index $\left(\mathrm{kg} / \mathrm{m}^{2}\right)$ & $(52.9-94 \cdot 7)$ & $(47 \cdot 5-103 \cdot 5)$ \\
& 23.7 & $26 \cdot 1$ \\
& $(17 \cdot 9-31 \cdot 2)$ & $(18 \cdot 1-40 \cdot 3)$ \\
\hline
\end{tabular}

* Defined as the number of years between discontinuation of treatment and time of investigation. $\dagger$ Mann-Whitney $U$ test $(P<0.05)$. 

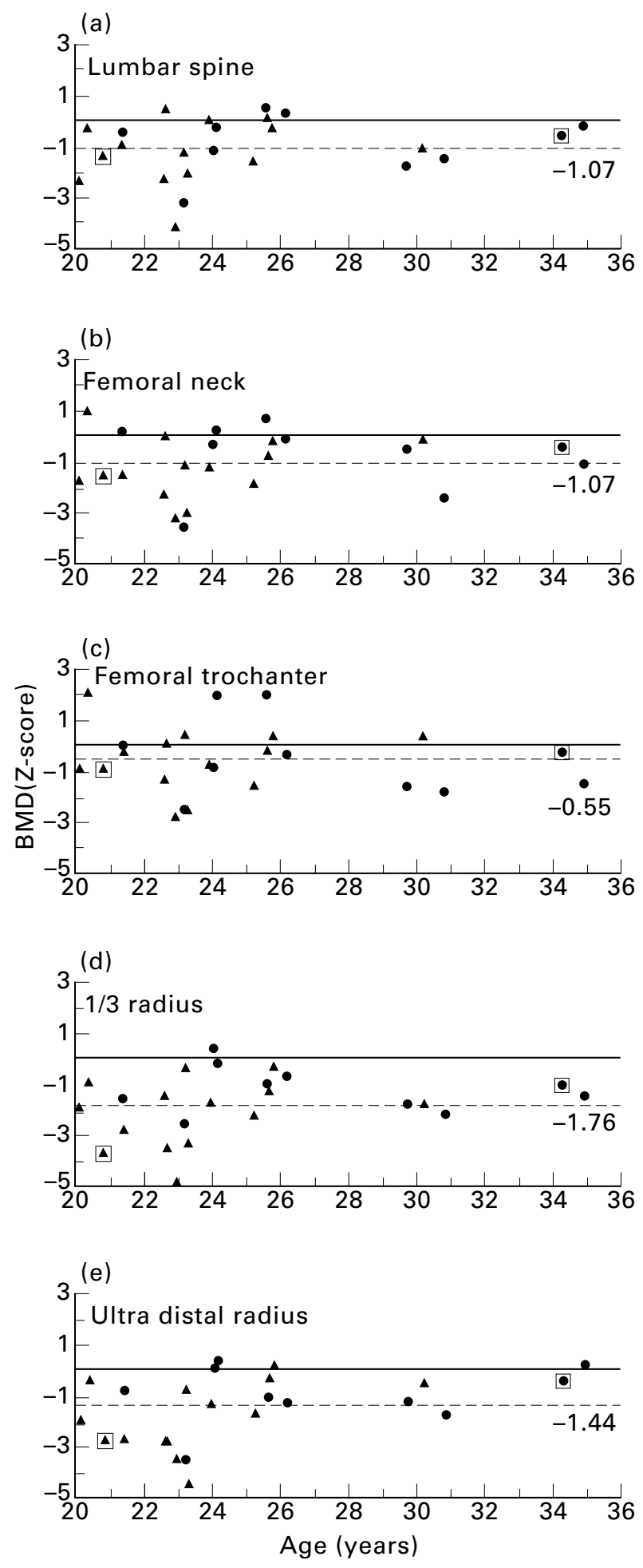

the time of study, there were no significant differences in the BMD values between males and females. The BMD Z-scores in the different areas correlated well with each other. No consistent differences in the BMD Z-scores were present between areas of predominantly trabecular bone, like the LS, FT and UD radius, and cortical bone, like the $\mathrm{FN}$ and $1 / 3$ radius.

Biochemical analysis showed $\mathrm{Ca}$ and $\mathrm{P}$ in the low-normal range (Ca: $2 \cdot 16-2.38 \mathrm{mmol} / 1$, reference range: $2 \cdot 20$ $2.60 \mathrm{mmol} / \mathrm{l} ; \quad \mathrm{P}: \quad 0.42-1.13 \mathrm{mmol} / \mathrm{l}$, reference range 0.70 $1.40 \mathrm{mmol} / \mathrm{l}$ ) and ALP in the normal range (36-89 U/l, reference range: <90 U/l). The values of LH, FSH and E2 $(n=5)$ or $\mathrm{T}$ values were within the normal adult range (E2: $111-500 \mathrm{pmol} / \mathrm{l}$, reference range $90-2100 \mathrm{pmol} / \mathrm{l} ; \mathrm{T}$ : 13 $-27 \mathrm{nmol} / \mathrm{l}$, reference range $>8 \mathrm{nmol} / \mathrm{l})$. The woman with primary amenorrhoea had an E2 value of $157 \mathrm{pmol} / \mathrm{l}$ (normal adult range). Mean IGF 1 and IGF-BP3 values were $22.3 \mathrm{nmol} / 1$ (range: $8 \cdot 8-37 \cdot 0$, reference range $9 \cdot 6-62 \cdot 8$ ) and $3.4 \mathrm{mg} / \mathrm{l}$ (range: $2 \cdot 4-4 \cdot 2$, reference range $2 \cdot 2-6 \cdot 6$ ) respectively; these values were in the low-normal range. Since these values decrease with increasing age, SDS-score values are of more value. Mean IGF-1 SDS-score was -1.24 (range -2.80 to +0.06 ; $95 \%$ CI: -1.59 to -0.89 ) and mean IGF-BP3 SDSscore was $-0,78$ (range -1.53 to $+0.06 ; 95 \% \mathrm{CI}:-1.03$ to -0.53 ), significantly below the reference values. There was no correlation between the IGF-1 SDS scores or IGF-BP 3 SDS scores and height. IGF-1 SDS scores and IGF-BP3 SDS scores did not correlate with BMD values in the different areas.

In 9 patients, GH stimulation tests were performed. Table 2 shows the different parameters of GH status in these patients. Height SDS and IGF-BP3 SDS in the tested patients were not statistically significant from the total study group; IGF-1 SDS was significantly lower in the subgroup. Three patients had a peak GH response of $\leq 10 \mathrm{mU} / \mathrm{l}$ both during the insulin tolerance test and the GHRH test, 1 patient had a peak GH response of $<10 \mathrm{mU} / 1$ in the GHRH test and $<15 \mathrm{mU} / 1$ in the insulin tolerance test, while 5 patients showed a reduced peak GH response in one of these tests.

With respect to the specific markers of bone turnover, levels of bone formation markers BALP, P1CP and osteocalcin in the patients did not differ from those in the control group (Table 3). The levels of the bone resorption markers 1CTP and $\mathrm{Ca} /$ creat ratio in patients and controls were in the same range.

Correlation analysis between the BMD Z-scores in the different areas (LS, FN, FT, 1/3 radius and UD radius) and the

Fig. 1 BMD values expressed as Z-score in the different regions. a, Lumbar spine; b, Femoral neck; c, Femoral trochanter; d, 1/3 radius; e, Ultra distal radius; - Female; $\boldsymbol{\Delta}$ Male. The patients marked with $\square$ did not receive cranial irradiation. - - - mean value for each site.

(C) 1999 Blackwell Science Ltd, Clinical Endocrinology, 50, 237-244 
Table 2 Parameters of GH status in a subgroup of 9 patients.

\begin{tabular}{|c|c|c|c|c|c|c|c|}
\hline Patients & Sex & Age (yrs) & Height-SDS & IGF-1 (SDS-score) & IGF-BP3 (SDS score) & ITT* & GHRH-test $\dagger$ \\
\hline 1 & M & 23.9 & $-0 \cdot 3$ & $-1 \cdot 6$ & $-1 \cdot 2$ & -- & -- \\
\hline 2 & $\mathrm{~F}$ & $30 \cdot 8$ & $-0 \cdot 8$ & $-2 \cdot 8$ & $-0 \cdot 2$ & - & -- \\
\hline 3 & $\mathrm{M}$ & $25 \cdot 2$ & $-1 \cdot 8$ & $-0 \cdot 1$ & $-0 \cdot 3$ & + & - \\
\hline 4 & $\mathrm{M}$ & $21 \cdot 4$ & $-1 \cdot 5$ & $-2 \cdot 4$ & $-1 \cdot 1$ & + & -- \\
\hline 5 & $\mathrm{~F}$ & $29 \cdot 7$ & -0.7 & -0.9 & $-1 \cdot 1$ & - & + \\
\hline 6 & $\mathrm{~F}$ & $26 \cdot 2$ & $-1 \cdot 3$ & $-2 \cdot 0$ & $-1 \cdot 5$ & -- & -- \\
\hline 7 & $\mathrm{M}$ & $20 \cdot 1$ & $-1 \cdot 8$ & $-1 \cdot 7$ & $-1 \cdot 0$ & -- & -- \\
\hline 8 & M & $23 \cdot 2$ & $-0 \cdot 6$ & $-2 \cdot 4$ & $-1 \cdot 5$ & - & + \\
\hline 9 & $\mathrm{M}$ & $22 \cdot 6$ & $0 \cdot 1$ & $-1 \cdot 8$ & $-1 \cdot 4$ & -- & + \\
\hline Mean & & $24 \cdot 8$ & $-1 \cdot 0$ & $-1 \cdot 8 \ddagger$ & $-1 \cdot 0$ & & \\
\hline
\end{tabular}

* Maximal GH response during an insulin tolerance test $(\mathrm{mU} / \mathrm{l}):--\leq 10 \mathrm{mU} / \mathrm{l} ;-\leq 15 \mathrm{mU} / 1 ;+\geq 15 \mathrm{mU} / \mathrm{l}$. $\dagger$ Maximal GH response during an GHRH test (mU/l): $--\leq 10 \mathrm{mU} / \mathrm{l}:-\leq 15 \mathrm{mU} / 1 ;+\geq 15 \mathrm{mU} / \mathrm{l}$. $\ddagger$ Mann-Whitney $\mathrm{U}$ test $(\mathrm{P}<0 \cdot 05)$.

cumulative dose of administered cytotoxic drugs: corticosteroids, vincristine, 6-mercaptopurine and methotrexate, as well as the irradiation dose did not show any correlation between BMD values and any of these cytotoxic drugs or the irradiation dose. Age at diagnosis and duration of follow-up were also not correlated with BMD.

Correlations of height-SDS and BMI with BMD at different skeletal sites, were positive for height with the LS only $(\mathrm{r}=0.40, P=0.053)$, in both male and female patients. In male and female patients BMI correlated positively with BMD in the $\mathrm{FN}(\mathrm{r}=0.45 ; P=0.03), 1 / 3$ radius $(\mathrm{r}=0.65 ; P<0.001)$ and UD radius $(\mathrm{r}=0.48 ; P=0.02)$.

\section{Discussion}

The young adult survivors of childhood lymphoblastic leukaemia in this study showed a significantly reduced BMD compared to age and sex-matched controls. 11 out of 24 patients had one or more Z-score values below minus 2. In both areas of predominantly trabecular bone (LS and UD radius) and areas of cortical bone (FN and $1 / 3$ radius) a significantly lower
BMD was measured. This indicates a generalised reduction in bone mass at all measured skeletal sites. The question arises whether the measured decreased bone mass in these young adults is the result of a limited period of disturbed bone development in the past or whether it is due to a persistent change in bone turnover. Since both markers of bone formation and bone resorption were normal, bone turnover was not disturbed at the time of the study.

In most individuals peak bone mass has been achieved at many skeletal sites by the age of 20 years (Ott, 1990; Sabatier et al., 1996). The study patients aged 20.1-34.9 had a lower bone density, although their bone turnover at this age was normal. Therefore, the decreased bone density in our expatients can be explained by an inadequate accumulation of bone mass in childhood and adolescence, most probably due to their previous disease or treatment.

There are several options to explain a reduced peak bone mass in survivors of childhood ALL, including the illness itself, cytotoxic treatment and cranial irradiation.

The disease ALL. Vertebral fractures with osteoporosis are
Table 3 Specific markers for bone formation, BALP, P1CP and osteocalcin and for bone resorption, ICTP and urinary $\mathrm{Ca} / \mathrm{crea}$, in patients compared to a control group.

\begin{tabular}{|c|c|c|c|c|c|}
\hline & \multicolumn{2}{|c|}{ Patients } & \multicolumn{2}{|c|}{ Controls } & \multirow[b]{2}{*}{$P$-value* } \\
\hline & Mean & Range & Mean & Range & \\
\hline $\mathrm{P} 1 \mathrm{CP}(\mu \mathrm{g} / \mathrm{l})$ & 139 & $67-327$ & 153 & $95-265$ & n.s. \\
\hline BALP (U/l) & $32 \cdot 7$ & $11 \cdot 2-61 \cdot 4$ & $26 \cdot 7$ & $10 \cdot 9-49$ & n.s. \\
\hline Osteocalcin $(\mu \mathrm{g} / \mathrm{l})$ & $2 \cdot 9$ & $0 \cdot 8-5 \cdot 9$ & $3 \cdot 1$ & $0 \cdot 4-6 \cdot 4$ & n.s. \\
\hline ICTP (nmol/l) & $4 \cdot 3$ & $2 \cdot 1-7 \cdot 0$ & $4 \cdot 3$ & $2 \cdot 4-7 \cdot 7$ & n.s. \\
\hline $\mathrm{Ca} /$ creatinine & $0 \cdot 26$ & $0 \cdot 06-0 \cdot 62$ & $0 \cdot 18$ & $0.02-0 \cdot 38$ & n.s. \\
\hline
\end{tabular}

* Student's $t$-test $(P<0.05)$. 
described in children with newly diagnosed ALL (Newman \& Melhorn, 1973; Samuda et al., 1987). These lesions are mostly attributed to infiltration and expansion of leukaemic tissues, leading to destruction of spongiosa. In addition, factors from malignant cells, like osteoblast inhibiting factor, prostaglandin $\mathrm{E}$ and ectopic parathyroid hormone, may play a role in the pathogenesis of a disturbed bone structure (Newman \& Melhorn, 1973; Samuda et al., 1987). Changes in mineral metabolism in association with a decreased bone mass, already present at diagnosis, suggest a defective mineralization caused by the disease itself (Halton et al., 1995). Some authors of short term studies assume that bone loss during the period of illness is reversible since improvement or even normalisation of bone mass is observed after treatment (Boot, 1997; Gilsanz et al., 1990). Based on our data, it remains to be established whether the disease ALL itself will have long term effects on bone mass.

Chemotherapy. Corticosteroids and methotrexate in particular are incriminated as drugs interfering with bone mineralization (Hahn et al., 1974; Sambrook \& Jones, 1995; Ragab et al., 1970; Nesbit et al., 1976; Schwarz \& Leonidas, 1984). Administration of high doses of corticosteroids is associated with both a decreased bone formation and an increased bone resorption, resulting in net bone loss (Hahn et al., 1974; Sambrook \& Jones, 1995; Halton et al., 1996). Methotrexate treatment is associated with a reduced bone mass and an increased fracture rate during maintenance treatment of ALL, which effect was reversed when methotrexate was stopped (Ragab et al., 1970; Schwarz \& Leonidas, 1984). We did not find a correlation between the BMD values and the cumulative dose of each cytotoxic drug separately; this does not exclude a combined effect of these drugs on bone mineralization. One of the 2 non-irradiated patients was treated with an intensified chemotherapy schedule; this might have contributed to the reduced BMD found in this patient.

Cranial irradiation. In treatment protocols for childhood ALL, used in the Netherlands before 1985, cranial irradiation was part of the treatment. This includes irradiation of the hypothalamic - pituitary area, which can impair the secretion of the hypothalamic and pituitary hormones (Shalet et al., 1988). A decreased vertebral density related to cranial irradiation is found in children approximately 3.5 years after stopping ALL treatment (Gilsanz et al., 1990). Sex steroids, GH and IGF-1 play a regulating role in bone formation (Gilsanz et al., 1988; Raisz, 1988; Kaufman et al., 1992; Holmes \& Shalet, 1996). All study patients had a normal sex steroid exposure, either with a normal endogenous gonadal axis, or as a result of sex steroid substitution (testosterone or oestrogens). With respect to the growth hormone axis, deficient growth hormone secretion is a well known late consequence of cranial irradiation (Moëll et al., 1988; Clayton et al., 1988; Shalet, 1989). GH deficiency acquired during childhood is associated with reduced peak bone mass (Kaufman et al., 1992; Hyer et al., 1992; Nussey et al., 1994; de Boer et al., 1994a). None of the study patients was known to have GH deficiency before the study, but in the study they were found to have a reduced mean IGF-1- and IGF-BP3 SDS score, which, in combination with a history of cranial irradiation is suggestive of GH deficiency.

We tested a subgroup of 9 patients with GH stimulation tests. These patients were selected because of their reduced BMD values or low IGF-1 SDS score. We speculated that these patients had developed a disturbed GH secretion. The diagnosis of GH deficiency is made when peak GH response to different forms of stimulation, most often an insulin tolerance test, is $<10 \mathrm{mU} / \mathrm{l}$ in most studies, although a cutoff of $15 \mathrm{mU} / \mathrm{l}$ has been used in some other studies (Johannson et al., 1997; Amato et al., 1996; de Boer et al., 1994a; Ogilvy-Stuart et al., 1994). The GH stimulation tests in our patients revealed an insufficient $\mathrm{GH}$ response $(<15 \mathrm{mU} / \mathrm{l})$ in at least one test in all tested patients.

Final height was significantly reduced in our patients. Several studies have demonstrated a normal height velocity after the period of ALL indicating normal GH release during the first years after cranial irradiation. The decreased final height which has been described in ALL patients treated with cranial irradiation, has been attributed to reduced height velocity during puberty as a result of increased demands for $\mathrm{GH}$ in this period and to early pubertal development (Logghe et al., 1988; Moëll et al., 1989). We suggest that GH deficiency in our patients has developed in late puberty or adolescence, which results in an inadequate accumulation of peak bone mass during this period (Gilsanz et al., 1988). Theoretically, an underestimation of bone density is possible in short subjects (Carter et al., 1992). However, since we found a correlation between height and the BMD of the LS only, we assume that if there is any effect of height on BMD, it will be limited.

As the quality of life in survivors of childhood malignancies becomes more important, late effects of radio- and chemotherapy should be given more attention. Our study supports the concept that osteopenia is one of these long term side effects; the exact mechanisms underlying this problem remains unresolved. To achieve an optimal peak bone mass in young survivors of childhood ALL, follow-up of bone mineral density, growth and parameters of growth hormone secretion during and after treatment is advisable. In case of endocrine disorders, hormonal replacement will be needed. In addition, intervention should also be considered in young patients with osteopenia, in order to improve peak bone mass.

In conclusion, the present study demonstrates that young adult survivors of childhood acute lymphoblastic leukaemia had disturbed bone development, which results in significantly reduced bone mineral density. Years after the illness, bone 
turnover is normal. The underlying mechanisms are multifactorial; in the studied patient group impaired growth hormone secretion plays a role. Patients cured of acute lymphoblastic leukaemia should be followed-up for the long term effects on growth, $\mathrm{GH}$ secretion and bone mass.

\section{Acknowledgment}

We gratefully acknowledge Dr. A. A. Bouman from the Labatory for Clinical Chemistry for determining BALP and E. Schouten and L. T. M. Rekers-Mombarg for assisting in the statistical analysis.

\section{References}

Amato, G., Izzo, G., La Montagna, G. \& Bellastella, A. (1996) Low dose recombinant human growth hormone normalizes bone metabolism and cortical bone density and improves trabecular bone density in growth hormone deficient adults without causing adverse effects. Clinical Endocrinology, 45, 27-32.

Boot, A.M. (1997) Bone mineral density and body composition of children and adolescents in health and disease. PhD. Thesis. Department of Paediatrics, University of Rotterdam.

Boot, A.M., de Ridder, M.A.J., Pols, H.A.P., Krenning, E.P. \& de Muinck Keizer-Schrama, S.M.P.F. (1997) Bone mineral density in children and adolescence: relation to puberty, calcium intake and physical activity. Journal of Clinical Endocrinology and Metabolism, 82, 57-62.

Bouman, A.A., de Ridder, C.M., Nijhof, J.H., Netelenbos, J.C. \& Delemarre-vd Waal, H.A. (1996) Immunoadsorption assay for bone alkaline phosphatase compared with wheat germ agglutinin precipitation assay in serum from (pre)pubertal girls. Clinical Chemistry, 42, 1970-1974.

Carter, D.R., Bouxsein, M.L. \& Marcus, R. (1992) New approaches for interpreting projected bone densitometry data. Journal of Bone and Mineral Research, 7, 137-145.

Clayton, P.E., Shalet, S.M., Morris-Jones, P.H. \& Price, D.A. (1988) Growth in children treated for acute lymphoblastic leukaemia. Lancet, 460-462.

de Boer, H., Blok, G.J., van Lingen, A., Teule, G.J.J., Lips, P. \& van der Veen, E.A. (1994a) Consequences of childhood-onset growth hormone deficiency for adult bone mass. Journal of Bone and Mineral Research, 9(8), 1319-1326.

de Boer, H., Blok, G.J., Popp-Snijders, C. \& van der Veen, E.A. (1994b) Diagnosis of growth hormone deficiency in adults. The Lancet, 343, 1645-1646.

Gilsanz, V., Gibbens, D.T., Carlson, M., Boechet, M.I., Cann, C.E. \& Schultz, E.E. (1988) Peak trabecular vertebral density: a comparison of adolescent and adult females. Calcified Tissue International, 43, 260-262.

Gilsanz, V., Carlson, M.E., Roe, T.F. \& Ortega, J.A. (1990) Osteoporosis after cranial irradiation for acute lymphoblastic leukaemia. Journal of Pediatrics, 117, 238-244.

Hahn, T.J., Boisseau, V.C. \& Aviolo, L.V. (1974) Effect of chronic corticosteroid administration on diaphyseal and metaphyseal bone mass. Journal of Clinical Endocrinology and Metabolism, 39, 274282.

(C) 1999 Blackwell Science Ltd, Clinical Endocrinology, 50, 237-244
Halton, J.M., Atkinson, S.A., Fraher, L., Webber, C.E., Cockshott, W.P., Tann, C. \& Barr, R.D. (1995) Mineral homeostasis and bone mass at diagnosis in children with acute lymphoblastic leukemia. Journal of Pediatrics, 126, 557-564.

Halton, J.M., Atkinson, S.A., Fraher, L., Webber, C., Gill, G.J., Dawson, S. \& Barr, R.D. (1996) Altered mineral metabolism and bone mass in children during treatment for acute lymphoblastic leukemia. Journal of Bone and Mineral Research, 11, 1774-1783.

Hoorweg-Nijman, J.J.G., Delemarre-van de Waal, H.A., de Waal, F.C. \& Behrendt, H. (1992) Cyclophosphamide-induced disturbance of gonadotropin secretion manifesting testicular damage. Acta Endocrinologica, 126, 143-148.

Holmes, S.J. \& Shalet, S.M. (1996) Role of growth hormone and sex steroids in achieving and maintaining normal bone mass (Review). Hormone Research, 45, (1-2): 86-93.

Hyer, S.L., Rodin, D.A., Tobias, J.H., Leiper, A. \& Nussey, S.S. (1992) Growth hormone deficiency during puberty reduces adult bone mineral density. Archives of Disease in Childhood, 67, 1472-1474.

Johannsson, G., Rosén, T. \& Bengtsson, B. (1997) Individual dose titration of growth hormone $(\mathrm{GH})$ during $\mathrm{GH}$ replacement in hypopituitary adults. Clinical Endocrinology 27, 571-581.

Johnston, C.C. \& Slemenda, C.W. (1993) Determinants of peak bone mass. Osteoporosis International (suppl) 1: 54-55.

Kaufman, J-M., Taelman, P., Vermeulen, A. \& Vandeweghe, M. (1992) Bone mineral status in growth hormone deficient males with isolated and multiple pituitary deficiencies of childhood onset. Journal of Endocrinology and Metabolism, 74, 118-123.

Kelly, T.L. (1990) Bone mineral density reference databases for American men and women. Journal of Bone and Mineral Research, 5 (supp 2), ppS249.

Kirschner, N.S., Voinchet, O. \& Rosenberg, I.H. (1978) Growth retardation in inflammatory bowel disease. Gastroenterology, 75, 504-511.

Logghe, K.A., Bourguignon, J.P., Craen, M. \& Benoit, Y. (1988) Factors contributing to the impairment of growth in children with acute lymphoblastic leukemia. Hormone Research, 30, 62-67.

Mazess, R.B., Barden, H.S., Bisek, J.P. \& Hanson, J. (1990) Dual energy x-ray absorbtiometry for total body and regional bone mineral density and soft tissue composition. American Journal of Clinical Nutrition, 51, 1106-1112.

Moëll, C., Garwicz, S., Marky, I., Mellander, L. \& Karlberg, J. (1988) Growth in children treated for acute lymphoblastic leukemia with and without prophylactic cranial irradiation. Acta Paediatrica Scandinavia, 77, 688-692.

Moëll, C., Garwicz, S., Westgren, U., Wiebe, T. \& AlbertssonWikland, K. (1989) Suppressed spontaneous secretion of growth hormone in girls after treatment for acute lymphblastic leukaemia. Archives of Disease in Childhood, 64, 252-258.

Nesbit, M., Krivit, W., Heyn, R. \& Sharp, H. (1976) Acute and chronic effects of methotrexate on hepatic, pulmonary and skeletal systems. Cancer, 37, 1048-1054.

Newman, A.J. \& Melhorn, D.K. (1973) Vertebral compression in childhood leukemia. American Journal of Disease in Childhood, 125, 863-865.

Nussey, S.S., Hyer, S.L., Brada, M. \& Leiper, A.D. (1994) Bone mineralization after treatment of growth hormone deficiency in survivors of childhood malignancy. Acta Paediatrica Supplement, 399, 9-14.

Ogilvy-Stuart, A.L., Wallace, W.H.B. \& Shalet, S.M. (1994) Radiation and neuroregulatory control of growth hormone secretion. Clinical Endocrinology, 41, 163-168. 
Ott, S.M. (1990) Attainment of peak bone mass (Editorial). Journal of Clinical Endocrinology and Metabolism, 71, 1082A-C.

Ragab, A.H., Frech, R.S. \& Vietti, T.J. (1970) Osteoporotic fractures secondary to methotrexate therapy of acute leukemia in remission. Cancer, 25, 580-585.

Raisz, L.G. (1988) Local and systemic factors in the pathogenesis of osteoporosis. New England Journal of Medicine, 318, 818-827.

Roede, M.J. \& van Wieringen, J.C. (1985) Growth diagrams of 1980. Netherlands third nationwide survey. Tijdschrift voor Sociale Geneeskunde, 63 (suppl), 1-34.

Sabatier, J.P., Guaydier-Souquieres, G., Laroche, D., Benmalek, A., Fournier, L., Guillon-Metz, F., Delavenne, J. \& Denis, A.Y. (1996) Bone mineral acquisition during adolescence and early adulthood: a study in 574 healthy females 10-24 years of age. Osteoporosis International, 6, 141-148.

Sambrook, P.N. \& Jones, G. (1995) corticosteroid osteoporosis. British Journal of Rheumatology, 34, 8-12.

Samuda, G.M., Cheng, M.Y. \& Yeung, C.Y. (1987) Back pain and vertebral compression: an uncommon presentation of childhood acute lymphoblastic leukemia. Journal of Pediatric Orthopedia, 7, $175-178$.
Schwartz, A.M. \& Leonidas, J.C. (1984) Methotrexate osteopathy. Skeletal Radiology, 11, 13-16.

Shalet, S.M. (1989) Endocrine consequences of treatment of malignant disease. Archives of Disease in Childhood, 64, 1635-1641.

Shalet, S.M., Clayton, P.E. \& Price, D.A. (1988) Growth and pituitary function in children treated for brain tumours or acute lyphoblastic leukaemia. Hormone Research, 30, 53-61.

Tanner, J.M. (1962) Growth at adolescence, 2nd ed. Blackwell Science, Oxford.

Veerman, A.J.P., Hählen, K., Kamps, W.A., van Leeuwen, V., de Vaan, G.A.M., Solbu, G., Suciu, S., von Wering, E.R., van der Does-van den Berg, A. (1996) High cure rate with a moderately intensive treatment regimen in non-high risk childhood acute lymphoblastic leukemia: resutls of protocol VI from the Dutch Childhood Leukemia Study Group. Journal of Clinical Oncology, 14, 911-918.

Wahner, H.W. \& Fogelman, I. (1994) The evaluation of osteoporosis: dual energy X-ray absorptiometry in clinical practice. p128-129, p154-155. Cambridge University Press, Cambridge.

Wiske, P.S., Wentworth, S.M., Norton, J.A., Epstein, S. \& Johnston, C.C. (1982) Evaluation of bone mass and growth in young diabetics. Metabolism, 31, 848-854. 